\title{
Applied Information and Analytical Systems for Investigation of the Regional Economy
}

\author{
Olga Kozhevina \\ International Institute of Economics, Management and \\ Informational Systems \\ Altai State University \\ Barnaul, Russia \\ ol.kozhevina@gmail.com \\ Natalia Salienko \\ Bauman Moscow State Technical University \\ (National Research University) \\ Moscow, Russia \\ verno555@mail.ru
}

\author{
Alexey Yudintsev \\ International Institute of Economics, Management and \\ Informational Systems \\ Altai State University \\ Barnaul, Russia \\ a_yudintsev@mail.ru \\ Galina Troshkina \\ International Institute of Economics, Management and \\ Informational Systems \\ Altai State University \\ Barnaul, Russia \\ g_troshkina@mail.ru
}

\begin{abstract}
This paper considers the problems of developing and using applied information and analytical tools for solving regional development management problems. Russia's regions differ a lot, making this study highly relevant. Based on regional differences, it makes sense to develop analytical tools. The goal of this study is to integrate digital analytical technologies in the process of forecasting dynamics of regional processes given specifics of social and economic development of territories. The study is done within the framework of the "Digital Region" project. The study uses an inter-disciplinary approach fusing together applied computer science, econometrics, and cyber economics. The result of this study is the inter-country analysis of the digitalization of regional development. The paper justifies that the foreign digitalization experience has to be adapted to Russian specifics when developing and implementing the "Digital Region" project.
\end{abstract}

Keywords - digital transformation, regional economy, applied computer science, digital region, smart cities, socio-economic development of regions.

\section{INTRODUCTION}

Digital transformation affected the whole of society. Of high relevance are the problems of developing territories (regions), in particular, smart regions and smart cities. Building smart territories and a complex and multi-aspect problem can only be solved by integrating the regional Government, the business, the science, and society. The depth of technology radically changes the society, its traditions, and the entire system of manufacturing relations, as well as the processes of territory management. One has to keep in mind that the digital transformation implies a radical change of priorities and focuses on technological changes. Information technologies are required for collecting, analyzing, processing, and transferring information for solving the required managerial problems. Information technologies do not just allow digitizing business processes; they contribute to the transformation of the very essence of different organizations [1, 2, 3]. In many areas of the economy, the digitalization processes have become all-encompassing and irreversible.

\section{METHODS}

The methods that were used were classified into general scientific and special ones. The problem of digital transformation of regions is complex. In this regard, a systematic approach and econometric analysis, statistical and comparative methods, regional forecasting and programming were used.

\section{MAIN PART}

In October 2019, the Council for the Development of Digital Economy at the Federation Council proposed a new federal project called "Digital Region" that would be integrated into the "Smart city" project. The task of the "digital region" project is to create information systems for solving problems of the whole territories of the regions, including rural localities. By 2025, fifty smart cities are planned to appear in Russia. These cities would have an integrated digital management platform that would take 75 percent of all decisions of the management of city resources.

The study hypothesizes that the digitalization of regions will help to optimize their resource policies. On the one hand, it will allow increasing the quality of managing smart regions and cities. On the other hand, it will improve economic, technological, legal, and social security on the regions' level via digital transformation, thus enabling the regions' population's high living standards. Regional and municipal economics of Russia vary in the level of digital integration and readiness for the Digital Revolution [4, 5, 6]. The Federal project "Digital Region" (postponed for one year due to COVID-19) is one of the components of the "Digital 
economy" projects with the spending of 247.5 billion rubles in 2020-2024. The federal budget contributes 70.2 billion rubles to the project; the rest is provided by the regional budgets. The money is to be spent on constructing buildings using information modeling technologies, creating environmental monitoring and waste management information systems, and, most importantly, involving the citizens in the decision-making processes on the regional and city level using regional digital platforms. The "digital region" project aims to "ground" the federal digital initiatives in Russia's subjects. The declared main goal is the acceleration of integrating digital technologies in regions to improve the quality of state management and management of the housing and public utilities ("platform solutions", the systems of "sustainable smart city", software for transport system management). The project also features an environmental system for monitoring the environment and waste, and a medical system for body temperature monitoring and enforcing of the mask-wearing rules using video cameras, as well as a security system (the geographic information system "secure region," creation of unified response centers). The implementation of the project is to be evaluated by a number of metrics measuring the shares of federal subjects that adopted this or another system, provided the access of the citizens to the information about utility bills, environmental thermal monitoring maps, conducing monitoring of chronically ill individuals using digital services, and promoted the use of a unified fair card and enabled participation in the problems of the regional development using digital technologies.

The Austria government started the "Digital Austria" platform. The platform coordinates the government operations, regional and municipal authorities in the format of special commissions responsible for a number of directions. The directions are as follows: Information direction provides common access to the information from the government entities; Communication direction provides the exchange of information with the Government; Transaction direction implement government services and electronic document flow; Personalization direction enables targeted content based on citizens' requests.

South Korea started the e-government initiative in 1967. The goal is "Creative Economy"; the project "Smart Nation" and "Smart Secretary". The project aims at improving digital accuracy, providing offline and online government services, the "sensors-remote control-messenger-government service", Creating "intelligent government" from digital data, and the AI-powered "smart secretary". The e-government 3.0 is projected to be implemented by 2025 [7].

New Zealand. The goal of the "Digital Transformation" project is to make government services comfortable and accessible to the citizens. New Zealand will use AI for data collection and digital identification. The RealMe digital identification platform will provide safe access to all data, from medical records to driver's licenses. New Zealand has no centralized government managing transformation in the digital sphere. There are different teams working independently and later uploading finished solutions. To create temporary employment for the project teams, innovation labs have been opened. The work of the project teams is iterative, as the teams poll the citizens about the service developed at each stage of the development.
China is implementing the project "Internet Plus integration with traditional industries". Also, China adopted a four-stage strategy for developing e-government. The State Council of the RPC adopted the program Internet Plus to develop digital services. The Chinese Government puts a lot of emphasis on information transparency. The Internet Plus program will create a legislative basis for open government services. The final stage of the program is providing digital services on the municipal level. For communicating with citizens, third-party services, including social networks, will be used. According to that plan, the Chinese Government is to introduce a system of social credit for citizens by 2020 . For calculating the social score, the Chinese Government will track any activity of citizens and companies, including the use of mobile data and e-commerce services. Trustworthy citizens will get privileges, while non-trustworthy citizens will be sanctioned.

Canada. The Canadian Government released a project of providing government services using information technologies internationally dubbed the "e-government" project as early as in 1994. Having broken down the project into three stages, the Canadian Government set the goal of building the "e-government" in five years. Having applied the modular principle, the system was subdivided into four contours: the website of Canada providing access to the GOL (Government Online Initiative) context, an information Portal having sub portals, intermediary software comprised of a search engine, a system for automating business processes, the systems of integrating processes and data, infrastructure software comprised of a system for managing electronic and paper documents, electronic storage and system for Big Data management. Currently, as a result of the project implementation, the Canadian Government is working and interacting with the population directly via a strong information portal uniting as many as 500 websites.

Canada. The Canadian Government released a project of providing government services using information technologies internationally dubbed the "e-government" project as early as in 1994. Having broken down the project into three stages, the Canadian Government set the goal of building the "e-government" in five years. Having applied the modular principle, the system was subdivided into four contours: the website of Canada providing access to the GOL (Government Online Initiative) context, an information Portal having sub portals, intermediary software comprised of a search engine, a system for automating business processes, the systems of integrating processes and data, infrastructure software comprised of a system for managing electronic and paper documents, electronic storage and system for Big Data management. Currently, as a result of the project implementation, the Canadian Government is working and interacting with the population directly via a strong information portal uniting as many as 500 websites.

The United States started creating elements of the egovernment in the 1990s via the use of IT for re-engineering government managerial processes. An important feature of the office of e-government in the United States is the Council of Chief Information Officers (CIO) of the branch Federal Departments, whose work is very important for the development and implementation of e-government development strategy in the US. A key aspect of the development of e-government in the US is the flexibility of public service laws aimed at attracting professionals from the commercial IT sector to government structures in the short and 
medium-term, and there is a reverse process of training civil servants in commercial IT companies in order to establish partner networks for e-government projects and find the best ways to implement IT in the public sector.

Since 2007, smart cities are sprouting around Europe, South-East Asia, and the USA. According to Easypark's Top100 rating, two Russian megacities, Moscow and SanktPeterburg, were acknowledged as smart cities. The top 10 cities of the rating include Copenhagen, Singapore, Stockholm, Zurich, Tokyo, San Francisco, Amsterdam, Geneva, and Melbourne. Moscow and Sankt Peterburg occupy the 77-th and 88-th places, accordingly. The development factors of a smart city are as follows 1) digital economy; 2) electronic process management; 3) development of skills and digital competencies of the population; 4) Industry 4.0 technologies; 5) digital environment (educational, medical, public utilities, sports, government services and so on); 6) digital infrastructure; 7) digital finance technologies (fintech); 8) security (information, technological, legal, environmental).

«Smart Nation» is a project in Singapore having the following initiatives: 1 . Strategic national project (CODEX, epayment, secure life). 2. Urban life. 3. Transport. 4. Health. 5. E-government services. 6. Start-ups and business. What is CODEX? Core Operations Development Environment and eXchange (CODEX) is the digital platform that will enable the Government to deliver better digital services to citizens faster and more cost-efficiently. It comprises the following:

1. A Government Data Architecture for common data standards and formats that better enables seamless data sharing between agencies.

2. A systematic transfer of less sensitive Government systems and data onto the commercial cloud, enabling the use of cutting-edge private sector capabilities to develop digital services.

3. A Singapore Government Technology Stack (SGTS) comprising a suite of shared software components and infrastructure to enable more efficient and focused building of digital applications.

The advantages of CODEX. Re-usable digital components, including machine-readable data streams, middleware, and micro-services, will be shared across agencies so that developers can plug and play into these resources and focus their time and energy on building products to serve the public better. The adoption of common tools and standards within the Government and by vendors will reduce bugs and raise the quality, reliability, and security of services. The Government can use what the commercial cloud can offer in terms of scalability and reliability, as well as software services and tools, thus facilitating the public and the private sectors to work together to develop more user-centric services for society.

The megatrends of the regional digital transformation are the following: a) integration of three blocks: physical, digital, and biological; b) global breakthrough innovations; c) the scales of economic, social, and cultural changes, new institutional models.

Digitalization encompasses all spheres of production and captures even remote reaches of Russia, which explains the positive trend of the digital indexes. From study results, the Central and Northwestern Federal District keep the leading positions. Moscow and Sankt Petersburg retain high scores. The third place is occupied by the Ural Federal District, and the Siberian Federal district occupies the fourth place.

The advantages of the digital development of Russia's regions are the following:

1) reduction of digital inequality;

2) Providing economic security of the regions;

3) Improvement of the investment attractiveness and possibility of inter-regional integration;

4) Development of high-tech production sectors and better attractiveness of the regional labor market by creating new jobs and redistributing labor resources;

\section{5) Forming "smart" regions and "smart" cities.}

Each region uses its own solutions to organize digital processes. The tasks solved by the regions encompass healthcare, transportation, security, public utility sector, social sphere, and agriculture. For the population, the adoption of these software complexes would help to solve a whole number of severe problems like utilization of public services, accessing government services, increasing the security of the urban environment, thus making it more comfortable.

Digital processes are inherently linked to Big Data. However, regions are still at the stage of accumulating these data, often from heterogeneous information systems. However, this process will ultimately yield a unified information space. The further analysis of the acquired and accumulated data is a complex problem that can be solved using different applied analytical systems and methods. For transportation, the analysis of the accumulated data can help to solve urban traffic problems. In healthcare, the methods can predict seasonal epidemics and help with patients' diagnoses.

The data sets may include tens of variables with different dimensions, scales, and often not statistically independent.

In $[8,9]$, we proposed a number of metrics for evaluating the socio-economic development of Russia's regions based on technologies of multivariate data analysis using correlation, factor, and cluster analysis. This paper proposes a concept of the applied information and analytical system for investigating regional economy based on multivariate data analysis technologies.

The method is comprised of several stages:

1) Data normalization based on mean and standard deviation value for each sample that equalizes the scale for different parameters;

2) Correlation analysis of the normalized indicators;

3) Statistical factor analysis of the normalized indicators, allowing the switch to a new array of factors. The factors are statistically independent, and they are comprised of linear combinations of the original indicators. Generally, the number of factors is much less than the number of input variables;

4) Domain-specific interpretation of factors based on experts' estimates. On this stage, we propose using a domainspecific interpretation of factors to reveal their economic meaning; 
5) Building a rating model of the socio-economic development of Russia's regions based on the formed set of factors;

6) Using cluster analysis for finding groups of regions with similar socio-economic development.

Visualizing the results of multivariate data analysis is a separate complex problem. For example, if the original indicator space is low-dimensional, and two or three factors are formed based on factor analysis, standard business visualization utilities can be used. If space has more dimensions, like, for example, the analysis of economic security of Russia's regions, which yielded seven factors, then it is not possible to visualize these factors simultaneously. In this case, one can use a $2 \mathrm{D}$ or $3 \mathrm{D}$ section of the original 7D space.

To analyze the socio-economic state of Russia's subjects, the following factors were chosen: X1 - average nominal monthly wage (rubles.), X2 - per capita average monetary income (rubles), X3 - economically active population (thousands of people), X4 - number of unemployed (thousands of people), X5 - the volume of investment in the fixed assets (rubles in millions), X6 - retail turnover (rubles in millions), $\mathrm{X} 7$ - the amount of works in the construction sphere (rubles in millions).

Table 1 shows the composition and loading of the factors, meaningful value of the factors' loading over 0.7 .

\section{TABLE I. FACTOR LOADING}

\begin{tabular}{|c|c|c|c|c|c|c|c|}
\hline $\mathbf{F}$ & X1 & X2 & X3 & X4 & X5 & X6 & X7 \\
\hline $\mathrm{F} 1$ & 0.155 & 0.210 & $0 . .96$ & 0.77 & 0.86 & 0.90 & 0.90 \\
\hline $\mathrm{F} 2$ & 0.95 & 0.93 & 0.13 & -0.26 & 0.13 & 0.24 & 0.32 \\
\hline
\end{tabular}

The paper conducted an investigation of the degree of difference in the level of socio-economic development of Russia's subject at the beginning of 2015. Using multivariate data analysis, clusters of subjects in the factor space were formed. The proposed method of determining the difference degree of the level of socio-economic development within a cluster and clusters, in general, can be used to define the strategy of development of Russia's subject on the regional and federal levels.

This study considers the problem of determining the socioeconomic differentiation of the subjects of the Siberian Federal District. Based on the immediate data of the regional department of the Federal Statistics Service of the Altai district [10] that characterizes the economic and social situation of the Altai Territory, Krasnoyarsk territory, Zabaikalye territory, Novosibirsk Region, Omsk Region, Tomsk Region, Irkutsk Region, Kemerovo Region and the republics of Altai, Tuva, Khakassia, and Buryatia for the end of 2014, we conducted the difference of the socio-economic development using methods of cluster and factor analysis [11].

The following subspace of socio-economic parameters was considered: X1 — per capita income; X2 — per capita spending; X3 - gross payroll, average monthly values from January to November of 2014, rubles.; X4 - the amount of agricultural production for categories farms and households in 2014 (per capita), rubles.; X5 - the amount of performed construction works; X6 - retail turnover, rubles in millions;
X7 - number of employees; X8 - number of unemployed; X9 - number of the economically active population (aged 15 to 72), thousand people (average value per Q4 2014).

TABLE II. FACTOR LOADING

\begin{tabular}{|c|c|c|c|c|c|c|c|c|c|}
\hline F & X1 & X2 & X3 & X4 & X5 & X6 & X7 & X8 & X9 \\
\hline F1 & 0.76 & 0.82 & 0.22 & 0.13 & 0.84 & 0.98 & 0.98 & 0.83 & 0.97 \\
\hline F2 & -0.35 & -0.25 & -0.91 & 0.84 & -0.23 & 0.02 & 0.05 & 0.27 & 0.08 \\
\hline
\end{tabular}

In $[9,10]$, technologies of multivariate data analysis were applied to the task of investigating the level of economic security of the regions of Russia. In this case, the original array of social and economic indicators, according to the KarpovKorableva model, was extended. The array comprised 28 indicators and included the following factors: per capita GRP $(V 1)$; per capita industrial output $(V 2)$ - the volume of shipped locally produced good, the volume of performed works and services by three types of economic activities divided by the annual average population; per capita agricultural produce (V3) - agricultural produce volume over the annual average population; the fraction of process industries in the volume of shipped locally produces goods and services (V4) - the volume of the volume of locally produced goods in the sector of process industries to the volume of shipped goods and services locally made by three kind of economic activity, total percent; degree of the wear of fixed assets (V5); per capita retail turnover $(V 6)$; the volume of paid services per capita (V7); volume of innovation goods, works and services as a percent of the total volume of shipped goods, performed works and services (V8); consumer price index (V9); GRP energy capacity $(V 10)$; power consumption (total consumption by large, medium and small organizations) (V11); average annual population dynamics (V12) - the average population in the current year divided by the average population in the previous year, \%; natural population growth per 1000 people (V13); migration growth per 1000 people (V14); life expectancy at birth (V15); unemployment rate (V16); population real income (V17); average monthly per capita income $(V 18)$; rich to poor coefficient $(V 19)$; the ratio of average per capita monetary income of the population to the value of the poverty threshold (V20); fraction of the population earning below the poverty threshold (V21); the total area of private premises per one tenant $(V 22)$; crime rate per 100000 population (V23); investment in the fixed assets, $\%$ of GRP (V24) - the ratio of the investment in the fixed assets to the volume of GRP, \%; the share of foreign investment in the fixed assets $(V 25)$ - the ratio of direct foreign investments to total investment in the fixed capital, \%; fraction of the unprofitable companies ( $V 26)$; consolidated regional budget deficit (V27); consolidated regional budget income, $\%$ of $(V 28)$.

The factor analysis yielded a seven-dimensional factor space $f 1-f 7$.

The system of linear equations describing the relationship of factors vs. normalized variables $X 1-X 28$ is given by:

$$
\begin{gathered}
f 1=0,161 \cdot X 1+0,146 \cdot X 2+0,247 \cdot X 3+0,108 \cdot X 12 \\
\quad+0,234 \cdot X 24 . \\
f 2=-0,142 \cdot X 6+0,111 \cdot X 13+0,153 \cdot X 16+0,248 \\
X 19-0,218 \cdot X 20+0,209 \cdot X 25+0,152 \cdot X 26 .
\end{gathered}
$$




$$
\begin{gathered}
f 3=0,118 \cdot X 3+0,132 \cdot X 12+0,261 \cdot X 13+0,197 \cdot \\
X 16+0,153 \cdot X 21-0,227 \cdot X 22 .
\end{gathered}
$$

$$
f 4=-0,188 \cdot X 7+0,244 \cdot X 8-0,1 \cdot X 9+0,133 \cdot X 10+
$$
$0,169 \cdot X 11+0,117 \cdot X 12-0,101 \cdot X 13+0,234 \cdot X 18+0,45$.

$$
X 23+0,113 \cdot X 25 \text {. }
$$

$$
\begin{aligned}
& f 5=0,404 \cdot X 7+0,12 \cdot X 8+0,499 \cdot X 10+0,161 \cdot X 11 \\
& +0,132 \cdot X 14+0,129 X 18-0,149 \cdot X 21-0,163 \cdot X 26 .
\end{aligned}
$$

$$
\begin{gathered}
f 6=-0,171 \cdot X 3+0,285 \cdot X 4-0,186 \cdot X 8+0,449 \cdot X 9+ \\
0,187 \cdot X 11-0,117 \cdot X 12-0,239 \cdot X 13+0,277 \cdot X 22- \\
0,126 \cdot X 23-0,113 \cdot X 24 . \\
f 7=-0,302 \cdot X 5+0,147 \cdot X 6+0,217 \cdot X 8+0,227 \cdot X 11 \\
+0,374 \cdot X 12-0,354 \cdot X 14-0,102 \cdot X 15+0,124 \cdot \\
X 16+0,165 \cdot X 17-0,149 \cdot X 21-0,244 \cdot X 22+0,231 \cdot X 27 .
\end{gathered}
$$

However, linear combinations of (1)-(7) determining the relationships between the factors and $X 1-X 28$ cannot be explicitly applied.

\section{CONCLUSION}

1.By the degree of readiness to the "Digital Revolution" and the transfer to Industry 4.0, regions of Russia differ greatly.

2. Generally, all information systems are based on using data sets of economic data created based on expert evaluations without any statistical justification.

3. Multivariate data analysis technologies are widely applicable, including applications in the investigation of the economic security of Russia's regions.

4. A combination of cluster and factor analyses should be used to improve the fidelity of regional development forecasts.

\section{REFERENCES}

[1] E. Gorlacheva, A. Gudkov, I., Omelchenko, D. Koznov, "The Knowledge Management Capability of High-Technology Enterprises", IC3K 2017 - Proceedings of the 9th International Joint Conference on Knowledge Discovery, Knowledge Engineering and Knowledge Management, vol. 9, P. 131-138.

[2] E.N. Gorlacheva, A.G. Gudkov, I.N. Omelchenko, P.A. Drogovoz, D.V. Koznov, "Knowledge Management Capability impact on Enterprises Performance in Russian High-Tech Sector. 2018 IEEE International Conference on Engineering", Technology and Innovation, ICE/ITMC, 2018,. MLSD.P. 8436316.

[3] Y.M. Nikolskaya, V.V. Selivanov, I.N. Omelchenko, L.I. Rakhlina, "Increase of the methods of program-target planning of the knowledgeintensive sectors", Proceedings of 2018 11th International Conference "Management of Large-Scale System Development", MLSD.P. 8551855.

[4] A.V. Pilyugina, E.A. Erkovich, N.M. Suray, Yu.M. Buhteeva, N.V. Vasilievich, "Features of application of target programs for regional development", International Journal of Civil Engineering and Technology, 10(2), 2015, pp. 904-910.R. Berger, The Digital Transformation of Industry.

[5] O. Kozhevina, N. Salienko, V. Kluyeva, S. Eroshkin S., "Digital Readiness Parameters for Regional Economies: Empirical Research and Monitoring Results (Russia Case Study)", Advances in Intelligent Systems and Computing. Springer, 2019, Vol. 983, pp. 247-256. URL: https://doi.org/10.1007/978-3-030-19868-8_25/ $\quad$ (accessed 10.11.2020)

[6] O.V. Kozhevina, N.V. Salienko, E.A. Starozhuk, V.A. Klueva, I.V. Pavlova I.V., "Digital Transformation of the Industrial Sector: Challenges and Prospects. Scientific and Technical Revolution:
Yesterday, Today and Tomorrow", Lecture Notes in Networks and Systems, 2020, Vol. 129, Springer. pp. 530-539. DOI: 10.1007/978-3030-47945-9_58.

[7] SmartNation. URL: https://www.smartnation.gov.sg/ (accessed 10.11.2020).

[8] A.V. Pilyugina, A.V. Mischenko, "Models for assessing the production capacity of an enterprise. Herald of the Bauman Moscow State Technical University", Series Mechanical Engineering, 2017, Vol 114. pp. $102-121$.

[9] A.V. Pilyugina, "Modeling of the optimal structure of the enterprise's assets", Herald of the Bauman Moscow State Technical University, Series Natural Sciences, 2015, No 11. p. 140.

[10] G.N. Troshkina, A.Yu. Yudintsev, S.I. Mezhov, "Investigation of the dynamics of economic security of the regions of the Siberia Federal District for the period of 2014-2017 using multivariate data analysis methods", Russian economic Internet Journal, 2017, No 4. P. 131.

[11] A.Yu. Yudintsev, G.N. Troshkina, "Analysis of the economic security of the Russia's regions using multivariate data analysis methods of the year of 2016", Economic system management: electronic scientific journal, 2018, No 9 (115), P. 30. 